\title{
The Factors Affecting the Design of Electronic Products
}

\author{
Tian Shengcun \\ Tianjin Qibi Communication \& Broadcasting Co., Ltd. Tianjin 300462
}

\begin{abstract}
With the development of the times, the development of electronic products has also developed rapidly, which greatly promoted the improvement of people's quality of life. However, there are still many factors to be paid attention to in the design of electronic products. In this paper, based on the design characteristics of the analysis of the factors that need to be considered.
\end{abstract}

Keywords; electronic products; structural design; factors

\section{Introduction}

Nowadays, more and more electronic products are used in all walks of life, and the safety and service life of electronic products are paid more and more attention. And in order to protect the safety of electronic products and longer service life must ensure that the design principles of electronic products reasonable, while ensuring the accuracy of structural design ${ }^{1}$. This paper focuses on the requirements, principles and influencing factors of electronic product structure design. Through the electronic product structure design requirements, principles and the impact of factors for the future design of electronic products to provide a powerful help to protect the design of a more reasonable structure, higher security, longer life of electronic products.

\section{The characteristics of electronic products}

1.1 The composition of electronic products is quite complex, the density is very large

Electronic products are more sophisticated, its structure is complex, and the density is its main features. As the electronic product structure complex density, so the structural design requirements more reasonable.

\subsection{The work environment varied, external impact}

Electronic products work environment for the environment is more complex, relatively high temperature and humidity requirements, electromagnetic interference and other effects are relatively large and so on.

\subsection{The reliability requirements are very strict}

The main purpose of electronic products is to improve a variety of accurate data, so the reliability requirements are relatively high, accurate accuracy requirements.

\subsection{Functional requirements and accuracy requirements are very high}

Electronic products require higher operational control. Will be precision machinery applications, but also its development which is a significant feature.

\section{Electronic product structure design requirements and principles}

\subsection{The structural design requirements of electronic products}

Electronic product structure design requirements are generally reflected in the following aspects ${ }^{2}$ : The first is the functional requirements, electronic products as a commodity, in the structural design to reflect their own use value; The second is the product quality requirements, product appearance, environmental protection and other quality requirements determine the value of the product, help to achieve the economic benefits of electronic enterprises; The third is the product structure optimization, electronic product structure design involves technology, materials, connection, shape, location, size and other structural 
design elements, to find the best solution for structural optimization; The fourth is to achieve structural design innovation, the rapid development of modern electronic products and information technology, in the rapid development of modern society, electronic products update speed is quite fast, so the electronic product structure design to use creative thinking, the use of the most advanced electronic technology and equipment, to achieve the profitability of electronic products.

\subsection{The basic principles of electronic product structure design}

First, to achieve the desired function of the various components of the principle, based on the overall structure of the design, coordination of the relationship between the various structures to simplify the structure of electronic products to achieve a variety of structural functions; Second, follow the strength and stiffness requirements, design, reduce the stress concentration, improve the force to increase the strength of the shell material to conduct a comprehensive test to meet the required strength and stiffness; Third, to meet the manufacturing process and assembly requirements of the principle, in the structural design, to simplify Electronic products, parts and components configuration, improve product assembly performance, a reasonable division of the assembly unit to achieve the reasonable installation of parts; Fourth, to meet the principles of user aesthetic, electronic products not only have practical features, but cannot ignore the electronic products in beauty.

\section{Electronic product structure design should consider the factor analysis}

\subsection{Production and maintenance factors}

Electronic product structure design process, must follow the follow-up production and maintenance factors. In the design must ensure the follow-up production more reasonable, easy to follow-up production, to ensure the follow-up production more smooth and reasonable. At the same time, in the design, we must consider the subsequent maintenance of electronic products. Because an electronic product cannot be used in the problem, and the problem, it must be repaired, so the maintenance of more convenient electronic products more easily meet the requirements. This requires the designer to be considered in the structural design. Reasonable structural design, can be in the electronic product problems when the maintenance, to facilitate the maintenance, without destroying the body of electronic products ${ }^{3}$.

\subsection{Product performance factors}

The internal layout of electronic products directly affects the overall performance of electronic products. Designers in the electronic product structure design process, to its components layout, circuit board wiring and component parts layout and the relationship between the various elements to consider. Effectively avoid the unreasonable layout of components caused by mutual interference between the circuits. At the same time, but also with the specific circumstances of electronic products, its circuit board bearing capacity of the comprehensive consideration, to avoid overweight, damage to the circuit board, but also to keep the components and the source between a certain distances. Circuit board wiring process, to the public, high-frequency line impedance, grounding and other effects of the signal to consider, its impact on the wiring to a minimum. The distance to the component layout is controlled.

\subsection{User use factors}

Electronic product structure design of the most fundamental purpose is to serve the consumer, in its design process to the user's needs to consider. Electronic products and people's daily life is closely related, so to its full consideration of its safety, its production process of safe grounding and lightning protection grounding control, and the risk of electric shock to a minimum. At the same time, designers should also avoid external factors on the electronic product design process to interfere with the damage to parts to affect its life. Electronic products in the production and application process has a greater radiation, the user's daily health will have a serious impact $^{4}$. Pay attention to the electronic product structure design process of heat, fire and explosion and so on. The electronic product transport and storage links to control, to avoid improper management lead to explosion and other security risks.

\subsection{Product efficiency to achieve the factors}

The realization of the effectiveness of electronic products depends largely on the rationality of the internal layout of the product, so in order to achieve the pre-design of electronic products, it is necessary to consider the components layout, circuit board wiring, component parts layout, and the interaction among these three components. In the layout of components to overcome the problem of mutual 
interference between the circuit, taking into account the circuit board load limit, to avoid excessive lead to deformation of the circuit board or even broken, for the heat of the components to stay away from the source; in circuit board wiring, to consider the public, high-frequency line impedance, signal, ground and other factors on the signal to avoid the distribution of capacitance on the wiring interference; In the component parts layout, should take into account the geographical distance with the relevant factors.

\subsection{Product life factor}

The electronic product structure design must take into account the life factor. Users to buy electronic products is the first consideration is to long-term use $\mathrm{e}^{5}$. So to enhance the service life, electronic product designers must consider the important issue. And in order to protect the longer life, it must be designed more reasonable, more choice of parts parameters, material selection more secure and so on.

\section{Conclusion}

To achieve the electronic product structure design

need to consider a number of factors, as long as the electronic designers to accurately grasp the electronic product structure design factors, in order to achieve the desired effect of electronic products, electronic products more in line with people's needs to meet people's growing use needs electronic enterprises in the fierce market competition in an invincible position, access to rapid development.

\section{References}

[1] Zhang Xiaoyong. Research and Development of Knowledge Base System for Electronic Product Structure Design [D]. University of Electronic Science and Technology of China, 2012.

[2] Lee, H.M., Sundin, E. and Nasr, N., 2012. Review of end-of-life management issues in sustainable electronic products. In Sustainable Manufacturing (pp. 119-124). Springer Berlin Heidelberg.

[3] Zheng Haihang. Factors Affecting Electronic Products Design [J]. Equipment Manufacturing Technology, 2015,(11):258-259. [2017-09-21].

[4] Xiang Shengrong. Factors Affecting the Structure Design of Electronic Products[J/OL].

Practical Electronics, 2015,(04):102-104. (2015-03-18)[2017-09-21].

http://kns.cnki.net/kcms/detail/11.3571.tn.20150318.1

131.077.htmlDOI

10.16589/j.cnki.cn11-3571/tn.2015.04.179

[5] $\mathrm{Yu}$ Longfei. Structure Design of Electronic Communication Products [J]. Information Technology and Informatization, 2014,(11):47-48. [2017-09-21]. 